\title{
Redesigning Educational Systems Using IJAZA Structure
}

\author{
(Case study: Information Technology College)
}

\author{
Yasser Bahjat \\ Faculty of Computers and Information Technology, \\ King Abdulaziz University, \\ Jeddah, Saudi Arabia
}

\begin{abstract}
This paper discusses the use of IJAZA in an education system. The IJAZA system was the system used in the earliest Islamic nation for education and accreditation. The system was designed with a few major cultural concepts in mind. The basic principle of the IJAZA system is to give people complete freedom to study what they want, when they want it, from whomever they want, without any restrictions or influence from outside parties. To ensure the effectiveness of the system we think that the IJAZA system needs complete documentation of everything that happens within it, such as IJAZA documentation when it is first established, up to the performance review of the certified by the job market. Therefore, this paper provides a brief methodology, evaluation and implementation of the IJAZA system.
\end{abstract}

Keywords-IJAZA system; Islamic educational system; Apprentice studies

\section{INTRODUCTION}

The IJAZA structure was the educational system used in the ancient Islamic nation for education and accreditation [1-3].The origin of IJAZA system was that Muslims keened on learning and understanding the Holy Quran and the Hadith from highly scholars. When they master what they have learned, they will obtain the IJAZA "permission" to transmit the earned knowledge in the scholars' names. With passage of days this system had been used to obtain all kind of knowledge such as math, biology, chemistry ...etc.

The IJAZA system was designed with a few major cultural concepts in mind. These concepts included: Freedom to choose what to learn, education as a desire not a mandate, knowledge should always be cited to its originator and heritage should be preserved $[4,5]$. Based on that, we thought that reintroducing the IJAZA system while modifying it to take into account the few centuries that have passed would be a great idea to reenergize the educational systems of today.

The description of the idea of IJAZA is as follows (Fig. 1): a) Definition:

\author{
Ibrahim Albidewi \\ Faculty of Computers and Information Technology, \\ King Abdulaziz University, \\ Jeddah, Saudi Arabia
}

An IJAZA is the testimony of a scholar in a specific field that a licentiate is worthy of working in that specific field, and to give such an IJAZA to others is in many ways similar to an apprenticeship.

$$
\text { b) Age: }
$$

IJAZAs do not stipulate a minimum age for either the scholar or the licentiate.

c) Period:

An IJAZA is not linked to a certain period of time for completion nor is it linked to attending a minimum or maximum number of classes.

\section{d) Worthiness:}

A licentiate is given an IJAZA based on the personal evaluation by the scholar of his worthiness and is based on a specific result to a specific test.

\section{e) Lineage:}

Each IJAZA must clearly show the name of the licentiate, his scholar and the complete lineage of his IJAZA up to the founder of that IJAZA. This is the main contrast between the IJAZA system and an apprenticeship.

The wide implementation of the IJAZA system could be achieve much, such as a higher level of commitment from teachers to apprentice performance because an IJAZA is a testimony by the teacher to the licentiate, which incentivizes the teacher much more about his apprentice's performance as it would reflect directly on his personal reputation. Teachers are expected not to give an IJAZA to those who would affect his reputation negatively. Also, teacher development would improve since an IJAZA is a testimony from the scholar, and apprentices would always prefer receiving one from highly qualified scholars with strong reputations in their field. The job market would also prefer IJAZAs by scholars whose apprentices are known for their skill and professional performance (see Fig. 2), thus directly affecting the number of apprentices willing to study for his IJAZA. 


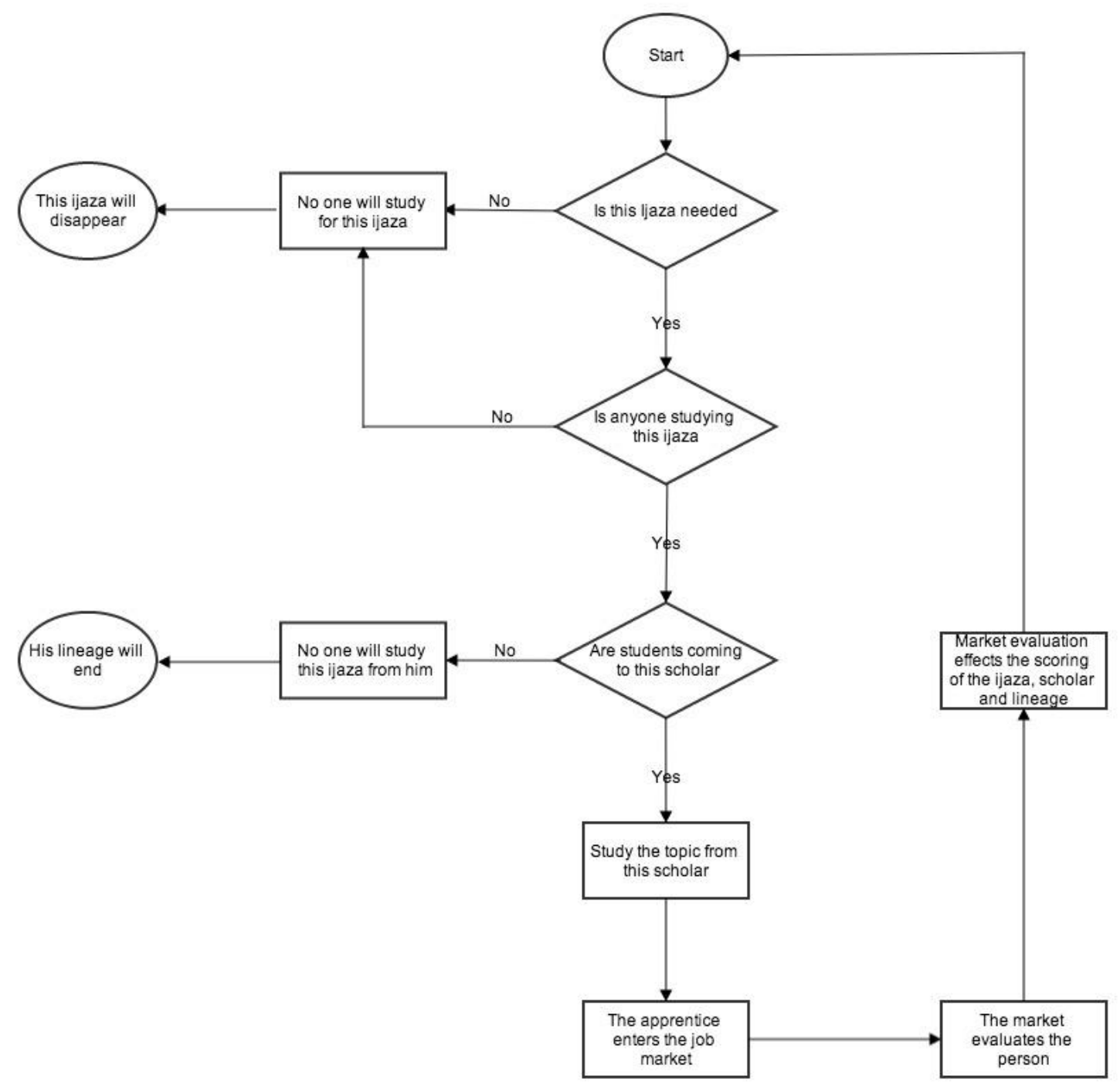

Fig. 1. IJAZA system guideline

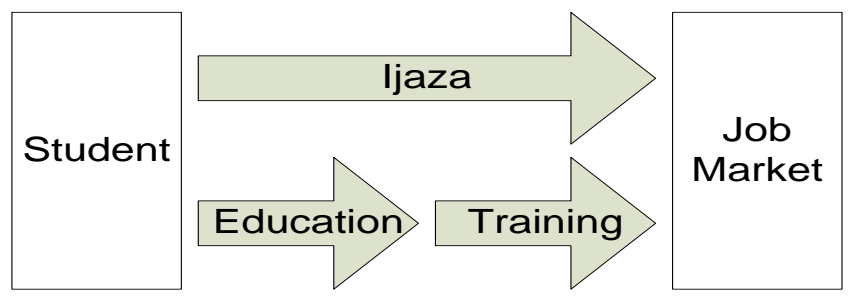

Fig. 2. Students' relation to the job market

Since an IJAZA does not depend on a specific time frame or regular attendance, the apprentices time to study and work simultaneously without either of them affecting the other, nor him needing to choose between the two since age is not a prerequisite for an IJAZA. Or an apprentice can get advanced IJAZAs at a young age allowing him to become a productive member in society instead of wasting his youth stuck a class room with zero productivity.
As the IJAZA is based solely on the discretion of the scholar, there are no restrictions on what the apprentice can or must learn from other fields. This also means that the apprentice can study from several scholars and receive the IJAZA from whomever he wants.

An IJAZA then is a true democratic system of education as the apprentice studies what he wants when he wants from whomever he wants. By allowing the apprentice to choose what he wants, the system allows each individual to be unique in a way he feels fits him, allowing him to highly specialize in any field or to be as multi-disciplined as he wants.

By giving this freedom to apprentices, they would tend to study what they are passionate about, ensuring that he would be more willing to go through hardships and have more knowledge. This would also ensure that his productivity in that field would be much higher as he is working in a field that he enjoys. 


\section{LITERATURE REVIEW}

The oldest democratic education system that still exists is Summerhill, in Suffolk, England. Summerhill is a free style school. The school's philosophy is to allow freedom for the individual - each child being able totake their own path in life, and following their own interests to develop into the person that they personally feel that they are meant to be. The freedom to attend formal lessons or not at the school is a central feature of the school's philosophy [6].

Sudbury Valley School, is also a democratic education system, Sudbury Model has three basic tenets: educational freedom, democratic governance and personal responsibility. At the Sudbury Valley School, students individually decide what to do with their time, and learn as an aside to their personal efforts, interactions and ordinary experience, rather than through classes or a standard curriculum. [7]

What differs IJAZA system is that although IJAZA system is democratic system which gives people complete freedom to study what they want, when they want it, from whomever they want without any restrictions or influence, butit has a level of formality since the student must attend the classes whether on regular or irregular basis. Because IJAZA implies that the student has learned this knowledge through face-to-face interactions "at the feet" of the scholar [8]. And the only way to obtain the IJAZA is to master what you have learned and to show commitment to your studies.

\section{IJAZA METHODOLOGY}

The basic principle of the IJAZA system is to give people complete freedom to study what they want, when they want it, from whomever they want without any restrictions or influence from outside parties (see Fig. 3), but while providing him with access to scholars and tools as needed. It is also based on the personal responsibility of both the teacher and apprentice by linking the apprentice to his scholar and his lineage, and expecting apprentices to take responsibility of seeking out knowledge and self-improvement.

To insure the effectiveness of the system, we think that the IJAZA system needs complete documentation of everything that happens within it, such as IJAZA documentation when it is first established, up to the performance review of the certified by the job market. The following describes the main documentation of the IJAZA system:

a) Title of the IJAZA.

b) Content description of the IJAZA and its specific knowledge base.

c) Skills (topics/subjects) that the licentiate has to be aware of, and memories or skills he must master.

d) Jobs that the licentiate can work in.

e) Evaluation methods that the scholar must follow to give the IJAZA to the licentiate.

f) Requirements needed to get the IJAZA.

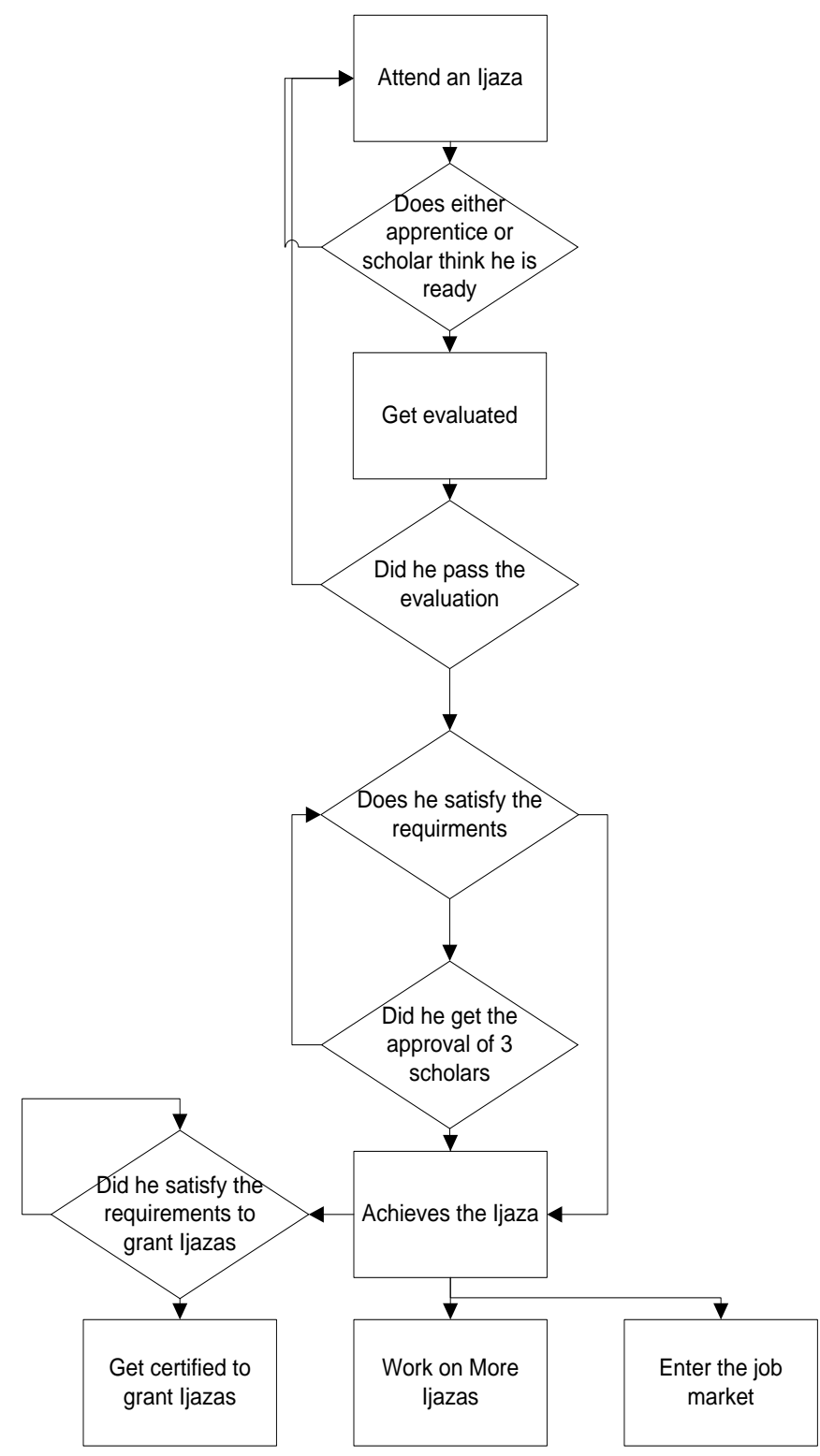

Fig. 3. IJAZA process

g) Requirements needed to be allowed to give the IJAZA to others.

h) Requirements needed to keep the IJAZA (Annual working hours, annual teaching hours, etc.).

i) Requirements and regulations for renewal of the IJAZA in the event that an IJAZA holder does not complete the requirements needed to keep his IJAZA.

The founder of any IJAZA has the right to set rules and requirements for anyone to get that IJAZA (e.g. that the apprentice has another IJAZA first, or a minimum duration of practice, a minimum duration between getting the IJAZA and him being allowed to give IJAZAs, minimum experience, etc.). 
The founder also has the right to waive such requirements and so can any other subsequent scholar provided he receives the approval of three other scholars who would approve such waiving. In such case the waiver's requirements have to be listed on his IJAZA and the scholars who had approved such waiver (in such case the apprentice's lineage is only connected to his scholar if one of those who approved the waver was the founder, and in such cases he is considered connected to the founder as well as his scholar).

Any IJAZA that starts its name with the word "Basic", such as "Basic Math", such IJAZAs do not allow its holder to give an IJAZA to anyone else. The sole purpose of such an IJAZA would be to build the basic foundation for the apprentice in the field. Any IJAZA that starts its name with the word "Advanced", such as "Advanced Math", endows the licentiate to teach the "Basic" IJAZA later.

\section{IJAZA EVALUATION}

The evaluation philosophy in the IJAZA system is unlike other systems. As the main objective of the evaluation in the IJAZA system is to allow the scholar to understand his apprentice's capabilities and grasp on the topic, in addition to his ability to self-develop in the field. Evaluation here is based on the apprentice's request to be evaluated as he thinks he is ready to get the IJAZA, or based on the scholar's request believing that his apprentice is now ready. This means that evaluation is usually done on an individual basis for each apprentice. We see that that are four appropriate ways of evaluation in the IJAZA system [9-10], however they all end in the same way as the scholar agrees to grant the IJAZA to his apprentice based on his sole discretion:

a) Written Exams: on the surface the idea of a written exam might seem similar to the current methods of evolution in our educational and certification systems, however it is drastically different in its objectives and approach. It starts in a similar way, with the scholar writing down a few questions that the apprentice must answer in writing as well. But the similarity ends there as the way such questions are prepared and how the apprentice's answers are evaluated is different.

- Questions: since the objective is to know whether the apprentice is a master in the field on which he is being evaluated and his ability to work in the field, and since the scholar, no matter how skillful and experienced he might be, would never be able to prepare his apprentice for every possibility that he would face in his professional career. We propose that at least a quarter of the questions should be from topics not covered under the topic of the IJAZA, allowing the scholar to evaluate his apprentice's ability to adapt \& innovate in addition to how his logic works when faced with things that he does not know.

- Evolution: when the scholar evaluates his apprentice's answers, he is not looking at it in the traditional manner of true and false and specific grades for each question, but as a detailed critique of those answers evaluating his methodology and style. He then discusses these comments with the apprentice and evaluates him based on his grasp of the topics covered in that exam. b) Professional Training: as the apprentice works for a period of time in his field, his scholar (along with the person with whom the apprentice worked) evaluates the apprentice's performance.. He then discusses that evaluation with the apprentice.

c) Project: the apprentice would choose a project from an idea of his own creation, and then his scholar would publically debate his apprentice, starting with the reasons why he selected that specific project up to the final results of the project. He would also open up the floor for any of the attendants to throw in their questions on the project.

d) Verbal evaluation: it is similar to the written exam in the type of questions and how they are evaluated, however it has to be done in public. This adds new aspects for the scholar to take into consideration when making his decision.

Our recommendation is to build a database for all IJAZAs and everyone who has an IJAZA along with the complete lineage. Every time one of them takes a job his employer can evaluate his performance allowing us to build up a score for the scholar who granted him the IJAZA and giving an indication of the strength of his lineage.

The database would work as follows:

a) Registering all IJAZAs and scholars along with the complete lineage.

b) Every time someone news is granted an IJAZA, his scholar enters his information and approves his IJAZA, linking his apprentice to his lineage.

c) When anyone with an IJAZA works, his employer evaluates him on the system.

d) The system calculates the score for every scholar based on the performance of his apprentices.

e) The entire lineage chain is affected with the score change of any of its members.

f) The system would allow anyone to browse through the lineages and see how they are scored allowing the job market to predict the mastery level of new IJAZAs.

\section{IJAZA IMPLEMENTATION}

We believe that before you start teaching anything to a student/apprentice using IJAZA system, we must first teach them how to read and write and all of the skills for him to master them. Reading is not only a human's ability to know the shapes of letters and produce the proper sounds related to them, nor writing just converting sounds into a shape on a paper. Surely such skill is necessary to achieve reading and writing, but it is but one of a list of skills that a human needs to become a reader or a writer.

Reading is the method through which you receive the knowledge that the writer intended to give to you along with the feelings related to it. On the other hand writing is a way to transmit such knowledge and feelings to others by moving your own thoughts out of your head and on to the paper.

Thus we propose to establish a nightly Kuttab that does not contradict with current school timings where scholars would work with students to give them these two IJAZAs: 
In this IJAZA a student would learn the shapes of letters and the proper pronunciations in addition to how to write them. A student cannot move on to the next IJAZA until he masters this one.

This IJAZA focuses on the student's ability to understand what he reads and write what he thinks and feels. The hall in which the scholar would teach his students would be a fullyfledged library with books from every field that he would use to empower his students in the different reading and writing skills that they need before he would grant them this IJAZA. Such skills include:

- Identifying the author's objectives and topic.

- Identifying the main topic and subtopics, and distinguishing between them.

- Understanding the meanings of words and structures.

- Giving a proper title to the material that they read.

- Reading properly without pronunciation errors.

- How the student interprets what he reads based on his prior knowledge and experience.

- The ability to use the dictionary to understand new words.

As previously mentioned, the paper proposes two types of IJAZA. "Basic" and "Advanced" IJAZAs. Basic IJAZA is recommended to be implemented inschools from elementary to high school and an advanced IJAZA to be implemented in higher education.

\section{A. Basic learning:}

You can consider this the IJAZA system's replacement for school from elementary to high school. We would recommend establishing what we call Majmaa' (Basic Science Center), where scholars would grant IJAZAs in Basic sciences in all fields such as math, biology, physics, literature, astronomy, history, etc. Students are encouraged to explore and pick whatever IJAZAs they want to achieve while providing guidance on the relationship and dependencies between them. Students are required to pass five subjects of their choice each year until they graduate.
In this way we will make sure that the students actually gained a proper education and they can contribute to science. The center must provide what the scholars might need such as books and tools to drive their teachings home and explain the practical aspects of their fields.

Initially such center would operate only in the evening not to conflict with current schooling times allowing parents to feel reassured that this new system would not negatively impact their children's futures.

\section{B. Advanced learning:}

You can consider this the IJAZA system's replacement for higher education and it allows students to specialize and delve deep into the knowledge areas they are passionate about. As a start, we want to establish an advanced IJAZA center for one of the fields. Students are required to have achieved one or more IJAZAs in basic sciences. This type of IJAZA will be given only to the students who master what they have learned. This type of IJAZA is equivalent to diploma and with this IJAZA students will be qualified to transmit this knowledge or to enter the job market and compete, since they have learned from professionals and those professional have certified that they are capable of working in this specific field.

This allows us to provide a higher education to those who were unable to go to college or those who achieved one of those basic IJAZAs to specialize and enter the job market, for example in the IT field as shown in Fig. 4.

\section{CONCLUSION}

This paper discusses the use of IJAZA in an education system. We consider the IJAZA system as a replacement for school from elementary to high school. Therefore, it is important that this paper does not stop with the philosophical discussion of academics, to then face the harsh reality that would provide thousands of obstacles and reasons why such system cannot be implemented on a large scale. That is why we are proposing in this paper a methodology of how such a system can be implemented today, even if on a small scale where we can measure its results and provide solid data on its effectiveness. 


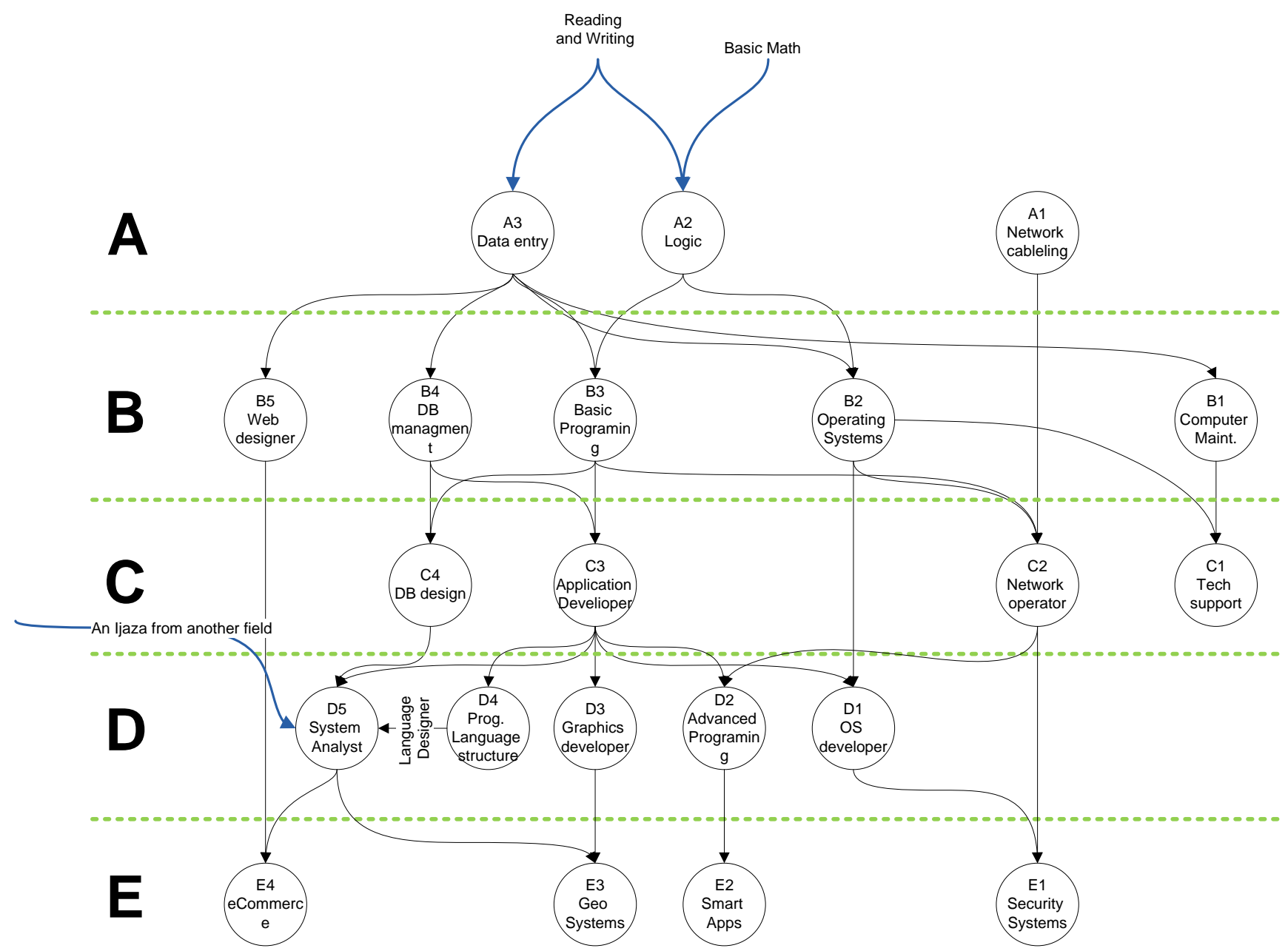

Fig. 4. Proposed Information Technology IJAZA structure

\section{REFERENCES}

[1] M. Halstead,“An Islamic concept of education,” Comparative Education, vol. 40, no.4, pp.517-529, 2004.

[2] Y. Waghid, "Conceptions of Islamic education: pedagogical framings," Global Studies in Education. vol. 3, 2011.

[3] M. S. Merry, Culture, Identity, and Islamic Schooling: A Philosophical Approach. Palgrave Macmillan, 2010.

[4] A. Hassan, A. Suhid,N. Z. Abiddin, H. Ismail, \&H. Hussin,"The role of Islamic philosophy of education in aspiring holistic learning," ProcediaSocial and Behavioral Sciences, vol. 5, pp. 2113-2118, 2010.

[5] M. A. Lubis, M. M. Yunus, M. Diao,T. Arifin, R.M. Muhamad, N. M. Ishak,"The perception and method in teaching and learning Islamic education," International Journal of Education and Information Technologies, vol.1, no.5, pp. 69-78, 2011

[6] Summerhill. "About Summerhill." Internet: http://www.summerhillschool.co.uk/about.php, [April 14, 2014].

[7] Sudbury Valley School. "About SVS." Internet: http://www.sudval.org/01_abou_01.html, [April 14, 2014].

[8] G. William,"Tranditinalism in Islam: An Essay in Intereption,” Journal of Interdisciplinary History, vol. 23, No.3, pp. 495-522, 1993.

[9] Flagg,N.Barbara. Formative evaluation for educational technologies. Routledge, 2013.

[10] Beetham, Helen, and R. Sharpe, eds.Rethinking pedagogy for a digital age: Designing for $21 \mathrm{st}$ century learning. routledge, 2013. 